\title{
POLÍTICAS PÚBLICAS PARA A PESSOA COM DEFICIÊNCIA - O CENTRO ESPECIALIZADO EM REABILITAÇÃO DO MUNICÍPIO DE DUQUE DE CAXIAS/RJ
}

\author{
Daniela Gonçalves De Carvalho ${ }^{1}$
}

\section{Resumo:}

Este paper apresenta a pesquisa debruçada sobre os Centros Especializados em Reabilitação, uma política pública de saúde, que visa atender a pessoa com deficiência. Cuida-se de verba destinada ao governo federal para manter centros de atendimento multidisciplinares às pessoas deficientes para os Municípios/Estados que apresentem os melhores projetos. $\mathrm{O}$ município de Duque de Caxias, um dos mais carentes do Estado do RJ, foi um dos contemplados. Neste trabalho, vamos analisa-lo com a finalidade de desvendar o funcionamento desse Centro e saber se já é possível analisar a política em si.

Palavras-chave: Políticas Públicas, Pessoa com Deficiência, Centros de Reabilitação, Repasse de Verbas Federais, Município.

\section{PUBLIC POLICIES FOR THE PERSON WITH DISABILITIES - THE SPECIALIZED CENTER FOR REHABILITATION OF THE MUNICIPALITY OF DUQUE DE CAXIAS/RJ}

\begin{abstract}
:
This paper presents the research on Specialized Centers in Rehabilitation, a public health policy that aims to serve people with disabilities. Funds are allocated to the federal government to maintain multidisciplinary care centers for people with disabilities for municipalities / states that present the best projects. The municipality of Duque de Caxias, one of the poorest in the state of Rio de Janeiro, was one of those contemplated. In this paper, we will analyze it in order to unveil the operation of this Center and to know if it is already possible to analyze the policy itself.
\end{abstract}

Keywords: Public policy, Person with Disability, Rehabilitation Centers, Transfer of Federal Funds, County.

\section{INTRODUÇÃO}

A pesquisa aqui exposta procura investigar a aplicação prática de uma política pública voltada às pessoas portadoras de deficiência. A inclusão de todas as pessoas é expressa na Constituição. No artigo 3. ${ }^{\circ}$, IV, prescreve-se a promoção do bem de todos, sem preconceitos

\footnotetext{
1 Mestranda no PPGD - UNIRIO - Mestrado em Direito e Políticas Públicas da Universidade Federal do Estado do Rio de Janeiro. Procuradora Federal.
} 
de origem, raça, sexo, cor, idade e quaisquer outras formas de discriminação. O artigo $5 .^{\circ}$, que concentra sabidamente os principais direitos fundamentais na Constituição Republicana, traz a igualdade substancial em seu caput.

Seguindo a vontade constitucional, O Estatuto da Pessoa com Deficiência (Lei 13.146/2015) veio regulamentar a Convenção de Nova York, Tratado de Direitos Humanos de que o Brasil é signatário, o qual tem força de Emenda à Constituição (CRFB, art. 5. , parágrafo 3 . $^{\circ} \mathrm{c} / \mathrm{c}$ Decreto n. ${ }^{\circ}$ 6.949/2009). A pessoa com deficiência tem ganhado notável espaço em discussões mundiais sobre inclusão.

Mesmo antes do Estatuto da Pessoa com deficiência ser promulgado, o Ministério da Saúde, através da Portaria n. ${ }^{\circ}$ 793, de 24 de abril de 2012, criou a Rede de Cuidados à Pessoa com Deficiência. Dentre muitos aspectos dessa materialização de vontade do Constituinte e dos Países signatários da Convenção de Nova Iorque, nasceram os CERs - Centros Especializados em Reabilitação. Com base no federalismo de cooperação, a ideia que partiu do poder central, contida na Portaria, fez com que o Ministério selecionasse os projetos dos municípios e Estados interessados, que, apresentariam as necessidades e melhores formas locais de implementação, para que recebessem esta verba com especial destinação. Eis a contextualização de um tema tão sensível aos dias hodiernos, e a problemática do trabalho.

O objetivo geral pode ser descrito como a análise de uma política pública que vem atendendo à população com deficiência de uma região muito carente. Sabe-se que há muitos complicadores internos, desde questões orçamentárias a empecilhos de ordem políticopartidária. Assim, o intuito da pesquisa é contribuir, com dados concretos e tomando o exemplo do que parece estar dando certo em Duque de Caxias a fim de contribuir com a evolução dos demais municípios, para superar uma dificuldade constante.

\section{1- A relevância de políticas Públicas voltadas às Pessoas com Deficiência}

A humanidade tem visto um aumento significativo da parte da população com deficiência. A título de exemplo, o autismo, síndrome que afeta vários aspectos da interação do indivíduo com os demais e o mundo à sua volta, vem atingindo alto número de incidência e merece uma atenção especial dos organizadores da Agenda Pública. De acordo com dados da Revista Espaço Aberto, da Universidade de São Paulo (USP): 
Segundo dados do CDC (Center of Deseases Control and Prevention), órgão ligado ao governo dos Estados Unidos, existe hoje um caso de autismo a cada 110 pessoas. Dessa forma, estima-se que o Brasil, com seus 200 milhões de habitantes, possua cerca de 2 milhões de autistas. São mais de 300 mil ocorrências só no Estadoel de São Paulo (OLIVEIRA, 2018, p. 1).

Em 2010, quando foi realizado o derradeiro Censo Demográfico, mais de 45 milhões de pessoas declararam ser portadoras de algum tipo de deficiência. Isto correspondia, já no ano de 2010, a 23,9\% da população brasileira. Ainda de acordo com informações publicadas pelo IBGE, pela Pesquisa de Informações Básicas Municipais de 2014, os Municípios, em sua maioria, não promoviam quaisquer políticas públicas de integração ou de acessibilidade como, por exemplo, turismo acessível $(96,4 \%)$, inclusão no mercado de trabalho $(72,6 \%)$, lazer para pessoas com deficiência (78\%) (LOSCHI, 2017).

A figura a seguir é bem didática no tocante aos percentuais de cada espécie de necessidade especial dentro dos níveis de deficiência populacional:

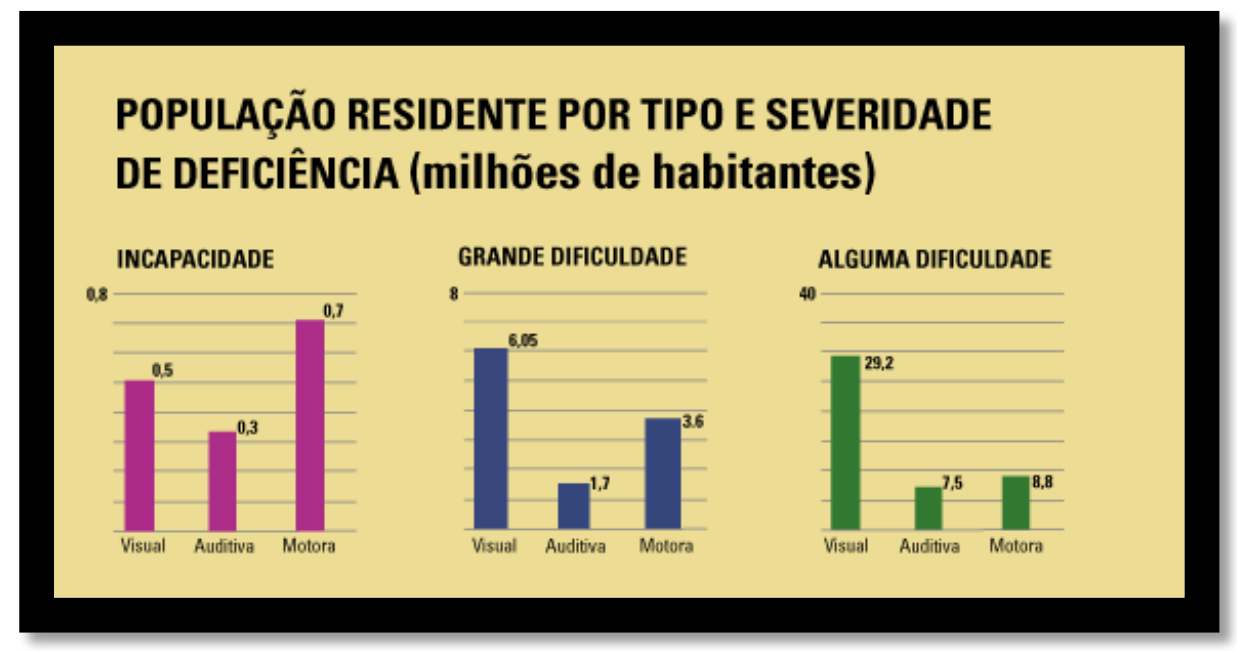

Figura 1 - População residente por tipo e severidade de deficiência

Fonte: Censo Demográfico (IBGE, 2010)

Assim, parece-nos oportuna a discussão e a relevância do estudo pormenorizado de uma política pública específica voltada a esta parcela tão significativa da população, e tão detalhada como o CER. É importante que o fulcro das políticas voltadas aos deficientes seja 
sempre a melhora da sua qualidade de vida e a sua integração de maneira cada vez mais significativa.

\section{2- Políticas Públicas voltadas à Pessoa com Deficiência em âmbito nacional}

A política pública é a tradução da política em si. Dependendo do seu teor, terá apoio de grupos sociais específicos e ojeriza de outros. Theodor Lowi foi quem primeiro desenvolveu esse tipo de raciocínio, estabelecendo conexões entre a política pública e a ideologia de classe, jogos de interesses. Todo o arcabouço permeável e astuto que está presente no jogo político, não fica de fora na hora de escolher e, também, de implementar as políticas públicas. As políticas públicas englobam leis, diversos atos administrativos e fatos que levam à realização de um determinado objeto, com fim específico (LOWI, 1964).

O Estado de bem-estar social, que se preocupa em prestar serviços públicos e chamar para si diversas atividades, por um lado, adquire legitimidade, ao se fazer presente. E, por outro, demanda mais gastos, o que faz aumentar o interesse não só em compreende-lo, mas, também em fiscalizá-lo. Precisamente neste ponto entra a nossa pesquisa: a Constituição Republicana de 1988 trouxe uma série de comandos que exigem diversos facere do Estado: não intervir em determinados setores sociais não é uma alternativa deixada pelo constituinte. Assim, tomando como ponto de partida o postulado da dignidade da pessoa humana, e da promoção à saúde (CRFB, arts. 1. ${ }^{\circ}$ e 196), encontramos o comando constitucional que obriga o ente público a desenvolver políticas que garantam melhor qualidade de vida à pessoa com deficiência.

Dentro do nosso trabalho, a agenda pública pode ser considerada a urgência na melhora da saúde, física e mental, e cada vez mais integração em todos os espaços, da pessoa com deficiência. A formulação e escolha da política advém da demanda social por melhorias e maior visibilidade a este segmento da população, o que vem ocorrendo desde a década de 1990.

A II Conferência de Saúde Mental no Brasil, seguida da assinatura da Declaração de Caracas ocorreram em 1990. Naquele ano, assistiu-se ao surgimento das primevas normas federais regulamentando a implantação dos serviços de atenção diária aos deficientes, 
fundadas nas experiências dos primeiros CAPS (Centro de Atenção Psicosocial) ${ }^{2}$ e Hospitaisdias. Também foram aprovadas as primeiras normas para fiscalização e classificação dos hospitais psiquiátricos. Tais novidades foram, no período de institucionalização da Reforma Psiquiátrica, marcos legais necessários e e garantias de novas práticas terapêuticas. (FONTE, 2012.)

Seguindo esta linha do tempo de formulação do atual Plano Nacional da Pessoa com Deficiência, importa mencionar a Lei Federal $\mathrm{n}^{\mathrm{o}}$ 10.216, de abril de 2001 (fruto da luta antimanicomial - lei da Reforma Psiquiátrica) acerca da extinção dos manicômios no seu antigo modelo de cárcere, criação de serviços substitutivos na comunidade e regulação da internação psiquiátrica compulsória. A lei da Reforma Psiquiátrica evidencia no art. $3 .^{\circ}$ a responsabilidade do Estado com desenvolvimento da política de saúde mental, a assistência e a promoção de ações de saúde aos portadores de transtornos mentais, devendo, sempre que possível, privilegiar a participação da sociedade e da família. Além disso, estabelece o conceito de estabelecimento de saúde mental: instituições ou unidades que ofereçam assistência em saúde aos portadores de transtornos mentais.

Deste modo, o cuidado para com a pessoa com deficiência e as obrigações de fazer daí decorrentes passam a ser consideradas juridicamente obrigações do Estado, concentradas no Plano Nacional. Trataremos como marco legal da implementação da Política Pública aqui estudada o referido e atual Plano Nacional de atenção ao Deficiente. As avaliações tomarão por base a experiência concreta do Munícipio fluminense de Duque de Caxias na implementação de CER - Centro Especializado de Reabilitação, levando em consideração dados estatísticos de atendimento e serviços ofertados, financiamento federal e projeto dos próprios profissionais de saúde do Município, tudo isso em razão da positividade de seus resultados. Buscaremos com o estudo de caso exemplificar esta política pública que envolve os dois entes federativos extremos: a União e os Municípios e desvendar de que modo isso pode ampliar o acesso aos deficientes aos serviços públicos de saúde multidisciplinar.

2 CAPS são unidades especializadas em saúde mental para tratamento e reinserção social de pessoas com transtorno mental grave e persistente. Os centros oferecem um atendimento interdisciplinar, composto por uma equipe multiprofissional que reúne médicos, assistentes sociais, psicólogos, psiquiatras, entre outros especialistas. (PREFEITURA MUNICIPAL DO RIO DE JANEIRO. Centro de Atenção Psicossocial (CAPS). Disponível em: 〈http://www.rio.rj.gov.br/web/sms/caps〉. Acesso em: 20 maio 2017). 


\section{1- Plano Nacional de Saúde da Pessoa com Deficiência}

O Plano Nacional de Saúde da Pessoa com Deficiência foi instituído através da Portaria n. ${ }^{\circ}$ 1.060, de 5 de junho de 2002. A Política Nacional de Saúde da Pessoa com Deficiência tem como fulcro a aplicar a inclusão das pessoas com deficiência em toda a rede de serviços do Sistema Único de Saúde (SUS) e buscar o reconhecimento da necessidade de implementar o processo de respostas às complexas questões que envolvem a atenção à saúde das pessoas com deficiência no Brasil. As diretrizes da Política Nacional expostas na Portaria acima mencionada consistem em promoção da qualidade de vida das pessoas com deficiência; assistência integral à saúde da pessoa com deficiência; prevenção de deficiências; ampliação e fortalecimento dos mecanismos de informação; organização e funcionamento dos serviços de atenção à pessoa com deficiência e, por fim, capacitação de recursos humanos.

O Ministério da Saúde é o órgão à frente do processo de formulação, implementação, acompanhamento, monitoramento e avaliação da política de saúde da pessoa com deficiência, observados os princípios e diretrizes do SUS, por meio de cooperação, convênios, assessoria técnica a Estados, a Municípios e ao Distrito Federal para o desenvolvimento de ações e da Rede de Cuidados à Pessoa com Deficiência no âmbito do SUS. Sendo o Ministro da Saúde a grande autoridade responsável pela política.

É possível ofertar ações e serviços de reabilitação em qualquer ponto de atenção da rede pública de saúde. Contudo, são nos Serviços Especializados em Reabilitação, como Centros Especializados em Reabilitação, onde esse tipo de serviço público especializado se concentra. As equipes são formadas por multiprofissionais como, dentre estes: psicólogos; médicos; fonoaudiólogos; fisioterapeutas; terapeutas ocupacionais; assistentes sociais.

Numa verdadeira materialização do federalismo de cooperação, considerando que os Serviços Especializados de Reabilitação configuram-se como pontos de atenção do componente Atenção Especializada em Reabilitação Auditiva, Física, Intelectual, Visual, Ostomia e em Múltiplas Deficiências, sendo estratégicos no processo de reabilitação para pessoas com deficiência temporária ou permanente; progressiva, regressiva, ou estável; intermitente ou contínua; a União criou os Centros de Reabilitação acima mencionados através Portaria n. ${ }^{\circ}$ 835, de 25 de abril de 2012, do Ministério da Saúde. 
A repartição vertical de competências na Constituição configura um relevante papel na implementação das políticas públicas. Atualmente, prega-se que o federalismo deve balizar a cooperação entre os entes federados, nos mais diversos setores.

Na medida em que há coordenação na Federação, temos várias formas de interdependência entre os agentes nos diversos âmbitos e nos diferentes planos de ação. Assim, o moderno conceito de 'federalismo cooperativo' mostrar-se-ia de certo modo redundante, pois, está implícito no conceito de federalismo (FARIAS, 1999, p. 305).

Estes Centros recebem verbas federais, através de repasses diretos do Ministério da Saúde à Secretaria de Saúde Municipal que é obrigada a aplicar o total da quantia e estão submetidas ao controle do Sistema Nacional de Auditoria do SUS (SNA) em cada nível de gestão e da Controladoria Geral da União (CGU). Mais detalhes sobre o Financiamento destes Institutos serão passados mais adiante.

\section{2- Centros Especializados em Reabilitação.}

Os Centros Especializados em Reabilitação consistem em locais de atenção ambulatorial especializada em reabilitação, física, mental e voltada para a independência e melhor qualidade de vida de pessoas portadoras de deficiência. Os CERs realizam diagnóstico, estimulação precoce, avaliação, orientação, e atendimento especializado, concessão, adaptação e manutenção de tecnologia assistiva, constituindo-se em referência para a rede de atenção à saúde no território do munícipio. O usuário é acolhido no CER por uma equipe multidisciplinar, após a realização de uma a triagem inicial, é elaborado um plano terapêutico a fim de proporcionar uma melhor qualidade de vida.

Há a possibilidade de firmar parcerias com instituições de ensino e pesquisa, de modo a contribuir ao avanço e a produção de conhecimento e inovação tecnológica em reabilitação. O projeto apresentado à União pelos municípios participantes, deve contemplar processos de educação permanente para as equipes multiprofissionais, garantindo atualização e aprimoramento profissional. Outra benesse a ser fornecida pelo ente federal é a 
disponibilidade de transporte sanitário, por meio de veículos adaptados, com objetivo de garantir o acesso da pessoa com deficiência aos pontos abrangidos pelo projeto.

Os Centros possuem as seguintes versões:

- CER II - composto por duas modalidades de reabilitação;

- CER III - composto por três modalidades de reabilitação e

- CER IV - composto por quatro modalidades de reabilitação.

Os Centros Especializados em Reabilitação devem ser planejados de forma a criarem agrupamentos que permitam flexibilidade, em especial para os CER II e III de ampliações futuras. Os módulos são: Física, Auditiva, Visual e Intelectual, aos quais são acrescentados os módulos de apoios, sendo que cada módulo possui os ambientes de acordo com as necessidades específicas

Há a necessidade de os munícipios apresentarem projetos que estejam em conformidade com o projeto-padrão disponibilizado pelo Ministério da Saúde. Cada tipo de CER possui um projeto-base para cada modalidade, de acordo com o número de especialidades que abranja. O CERII contempla sempre duas modalidades de deficiência que têm como especialidade, o CERIII, três, e o CER I, quatro mais as oficinas ortopédicas.

\section{3- Financiamento dos Centros Especializados em Reabilitação}

A Portaria n. ${ }^{\circ}$ 835, de 2012 do Ministério da Saúde instituiu incentivos financeiros de investimento e de custeio para o Componente Atenção Especializada da Rede de Cuidados à Pessoa com Deficiência no âmbito do Sistema Único de Saúde (SUS), segundo seu art. 1. ․ Os Estados, o Distrito Federal e os Municípios proponentes deverão relacionar nos projetos os ambientes a serem construídos, ampliados e/ou reformados, obedecida a estrutura mínima e a caracterização visual do CER e da Oficina Ortopédica, conforme requisitos obrigatórios definidos pelo Ministério da Saúde. As quantias serão liberadas pela União da seguinte maneira, através de convênio com o ente beneficiado (art. 2. $^{\circ}$, Portaria 835):

I - construção de Centro Especializado em Reabilitação (CER):

a) CER II -- R $\$ 2.500 .000,00$ (dois milhões e quinhentos mil reais) para CER com metragem mínima de $1000 \mathrm{~m}^{2}$;

b) CER III - R \$ 3.750.000,00 (três milhões setecentos e cinquenta mil reais) para CER com metragem mínima de $1500 \mathrm{~m}^{2}$; 
c) CER IV - R\$ 5.000.000,00 (cinco milhões de reais) para CER com metragem mínima de $2000 \mathrm{~m}^{2}$;

II - construção de Oficina Ortopédica: $\mathrm{R}$ \$ 250.000,00 (duzentos e cinquenta mil reais) para edificação mínima de $260 \mathrm{~m}^{2}$;

III - reforma ou ampliação para qualificação de CER II, CER

III - e CER IV - até R\$1.000.000,00 (um milhão de reais);

IV - aquisição de equipamentos e outros materiais permanentes:

a) CER II - até R \$1.000.000,00 (um milhão de reais);

b) CER III - até R $\$ 1.500 .000,00$ (um milhão e quinhentos mil reais);

c) CER IV - até R \$ 2.000.000,00 (dois milhões de reais); e

d) Oficina Ortopédica - até $\mathrm{R} \$ 350.000,00$ (trezentos e cinquenta mil reais).

Além dos projetos, são exigidos pelo Ministério da Saúde que os equipamentos e materiais permanentes a serem adquiridos devem estar em consonância com as listas prévias disponibilizadas no sítio eletrônico do Fundo Nacional de Saúde (FNS). As instalações físicas dos estabelecimentos de saúde deverão estar em conformidade com as Normas para Acessibilidade de Pessoas Portadoras de Deficiências a Edificações, Espaço, Mobiliário e Equipamentos Urbanos (ABNT, 2004).

O incentivo financeiro de investimento demonstrado acima será repassado pelo Fundo Nacional de Saúde em três parcelas, da seguinte maneira (art. 4. ${ }^{\circ}$, Portaria 835):

I - primeira parcela, equivalente a $10 \%$ (dez por cento) do valor total aprovado, será repassada após a publicação da portaria específica de habilitação do projeto apresentado;

II - segunda parcela, equivalente a $80 \%$ (oitenta por cento) do valor total aprovado, será repassada após autorização da SAS/MS, mediante apresentação dos seguintes documentos:

a) ordem de início do serviço, assinada pelo gestor de saúde local e por profissional habilitado pelo Conselho Regional de Engenharia, Arquitetura e Agronomia (CREA);

b) documento comprobatório da propriedade ou posse do terreno;

c) projeto básico de arquitetura aprovado pela Vigilância Sanitária, contendo memorial descritivo e cronograma físicofinanceiro da obra; e

III - terceira parcela, equivalente a $10 \%$ (dez por cento) do valor total aprovado, será repassada após nova autorização da SAS/MS, mediante apresentação de documento comprobatório da conclusão da edificação da unidade, assinado por profissional habilitado pelo CREA e pelo gestor de saúde responsável. 
Caso os recursos não sejam aplicados, ou sejam aplicados de maneira inadequada, ou, ainda, a não-realização da construção, reforma e/ou ampliação no período de 1 (um) ano após a transferência da segunda parcela, o Município/Distrito Federal deverá restituir ao Fundo Nacional de Saúde os recursos que lhe foram repassados, acrescidos de atualização monetária prevista em lei, cuja determinação decorrerá das fiscalizações promovidas pelos órgãos de controle interno, compreendendo os componentes do Sistema Nacional de Auditoria do SUS (SNA) em cada nível de gestão e a Controladoria Geral da União (CGU) - Art. 5. ${ }^{\circ}$, Portaria n. ${ }^{\circ} 835$.

Além do financiamento da construção ou reforma, a União oferece aos projetos vencedores os incentivos de custeio a seguir, os quais serão incorporados na forma de incentivo aos tetos financeiros dos Estados, Distrito Federal e Municípios (art. 7. ${ }^{\circ}$, Portaria $835)$ :

I - CER II - R\$ 140.000,00 (cento e quarenta mil reais) por mês;

II - CER III - R\$ 200.000,00 (duzentos mil reais) por mês;

III - CER IV - R \$ 345.000,00 (trezentos e quarenta e cinco mil reais) por mês;

IV - Oficina Ortopédica fixa - R \$ 54.000,00 (Cinquenta e quatro mil reais) por mês;

$\mathrm{V}$ - Oficina Ortopédica itinerante fluvial ou terrestre - $\mathrm{R} \$ 18.000,00$ (dezoito mil reais) por mês; e

VI - CEO - adicional de $20 \%$ (vinte por cento) calculado sobre o valor de custeio atual do serviço.

Os repasses acima ficam condicionados ao cumprimento das seguintes condições: prontuário único para cada paciente, contendo as informações completas do quadro clínico e sua evolução; condução da atenção aos usuários conforme diretrizes estabelecidas por instrutivos a serem disponibilizadas no sítio eletrônico http://www.saude.gov.br/sas; estrutura física e funcional e de equipe multiprofissional devidamente qualificada capacitada para a prestação de assistência especializada para pessoas com deficiência, constituindo-se como referência em habilitação/reabilitação, conforme requisitos disponíveis no sítio eletrônico http://www.saude.gov.br/sas; e equipe mínima composta por: médico; fisioterapeuta; fonoaudiólogo; terapeuta ocupacional; assistente social; e enfermeiro (art. 8. ${ }^{\circ}$, Portaria n. $\left.{ }^{\circ} 835\right)$. 


\section{3- CASO ESTUDADO - CER II - MUNICÍPIO DE DUQUE DE CAXIAS}

\section{1- Dados socioeconômicos do Munícipio estudado}

O CER estudado é o do Munícipio de Duque de Caxias, situado na Baixada Fluminense, uma das regiões mais carentes do Rio de Janeiro. O município tem uma área total de 467,6 quilômetros quadrados, correspondentes a 6,9\% da área da Região Metropolitana. Em 2010, Duque de Caxias tinha uma população de 855.048 habitantes, correspondente a 7,2\% do contingente da Região Metropolitana, com uma proporção de 92,6 homens para cada 100 mulheres. A densidade demográfica era de 1.828,5 habitantes por km2, contra 2.221,8 habitantes por km2 de sua região. A taxa de urbanização correspondia a $99 \%$ da população. Em comparação com a década anterior, a população do município aumentou 10,3\%, o 48 . $^{\circ}$ maior crescimento no estado (IBGE, 2010).

Já em relação ao IDH, será utilizado como critério o Índice de Desenvolvimento Humano Municipal (IDHM) é calculado pelo Programa das Nações Unidas para o Desenvolvimento (Pnud), pelo Instituto de Pesquisa Econômica Aplicada - Ipea e pela Fundação João Pinheiro (de Minas Gerais) com uma série de ajustes para se adaptar à realidade brasileira, consoante estudo socioeconômico do ano 2017 apresentado pelo Tribunal de Contas do Estado do Rio de Janeiro. ${ }^{3}$ O resultado divulgado em 2013, baseado nas informações do Censo 2010, está publicado no Atlas do Desenvolvimento Humano no Brasil 2013 (http://atlasbrasil.org.br/2013/). Dentro desta classificação, Duque de Caxias ocupa a 1.574. a posição em relação a 5.565 municípios do Brasil. Em relação aos outros municípios do Rio de Janeiro, está na 49. ${ }^{\text {a }}$ posição. Ou seja, pode ser considerada uma cidade de baixo índice de desenvolvimento humano.

O Total de receita líquida municipal previsto na Lei Orçamentária Anual para 2018 foi de R\$3.590.898,930, de acordo com informações da Transparência Municipal, para o Orçamento de 2018. Ainda, de acordo com a LOA, houve previsão dos seguintes gastos com saúde e pessoas com deficiência (LOA - DC/RJ - 2018):

3 TRIBUNAL DE CONTAS DO ESTADO DO RIO DE JANEIRO (TCE RJ). Secretaria Geral de Planejamento. Estudos Socioeconômicos. Municípios do Estado do Rio de Janeiro - 2017: Duque de Caxias. Disponível em: 〈http://www.tce.rj.gov.br/estudos-socioeconomicos1>. Acesso em: 11 de Junho de 2019. 
Fundo municipal de saúde - verbas recebidas pelo SUS $\mathrm{R} \$ 278.196 .592,00$.

Assistência ao portador de deficiência - 490.000,00 - valor que engloba construção de moradias populares ao deficiente e que não guardam relação com o CER.

Para o ano de 2017 a previsão foi de 3.384.863.357,00 (três bilhões, trezentos e oitenta e quatro milhões, oitocentos e sessenta e três mil, trezentos e cinquenta e sete reais). Para o ano de 2016, a receita estimada na LOA foi de 3.179.861.357,00 (três bilhões, cento e setenta e nove milhões, oitocentos e sessenta e um mil, trezentos e cinquenta e sete reais). No ano de 2017, foram reservados na LOA 128.000,00 para a assistência ao portador de deficiência, e no ano de 2016, $\mathrm{R} \$ 137.000,00$ foram reservados a este fim. Veremos adiante que esta verba não seria suficiente para manter um mês sequer de funcionamento do Centro de Atendimento Multidisciplinar.

\section{2- CER II Duque de Caxias ${ }^{4}$}

O CER II Duque de Caxias atende pessoas de São João de Meriti, Belford Roxo e Mesquita, além do próprio Munícipio. O atendimento é prestado de forma preventiva, através da estimulação precoce na faixa etária de 0 a 3 anos de idade. Dos 3 anos à terceira idade, o serviço é destinado às pessoas elegíveis à reabilitação. O CER oferece psicoterapias, fisioterapias, terapia ocupacional, atendimento médico, especializado em saúdes física, mental e reabilitação. Os beneficiários são pessoas com deficiências física e intelectual.

O quadro funcional do CER II Duque de Caxias é composto por 63 estatutários, dentre profissionais com vínculo municipal, estadual e federal. Além destes, há 20 colaboradores cooperativados e terceirizados.

De acordo com o Ministério da Saúde, o CER II recebe custeio anual de R $\$ 1,680$ milhão da União. Sendo certo que, no caso do Munícipio de Duque de Caxias, Todos os CERs do país recebem exatamente a mesma quantia. Ainda, segundo informações prestadas pela Diretoria não há noticia de contas reprovadas relacionadas ao CER. De modo que a verba é

4 As informações deste subitem foram obtidas junto à Diretoria do CER, por entrevista direta à funcionária da Diretoria Ângela Malaquias, em 07/05/2019, e exame da estatística da clínica fornecida pela mesma. 
utilizada nos termos da Portaria 835. As especialidades ofertadas são: acolhimento, clínica médica, colostomia, enfermagem, fisioterapia, fonoaudiologia, fisioterapia consolidada, geriatria, neurologia, nutrição, odontologia, ortopedia, pediatria, psicologia, psiquiatria, serviço social e terapia ocupacional.

Assim que recebeu o título, e as verbas, de CER II, a clínica atendeu, ao todo, em todas as especialidades 132.414 pacientes (ano de 2016). No ano seguinte, houve uma queda nos atendimentos, contudo, houve melhora qualitativa dos pacientes acompanhados, de acordo com informações da Diretoria, passaram a 98.134 atendidos. No ano de 2018, houve novo aumento nos atendimentos, tendo sido atendidos 100.408 pessoas. Os atendimentos foram feitos de acordo com a seguinte distribuição:

\begin{tabular}{|c|c|c|c|c|c|c|c|c|c|c|c|c|c|}
\hline & & & & & ANO. 2 & & & & & & & & \\
\hline ESPECIALIDADE & JAN & FEY & MAR & ABR & MAI & JUN & JUL & $\mathrm{AOO}$ & SET & OUT & NOV & DEZ & $\pi+\operatorname{tes} 2$ \\
\hline ACOLHIMENTO & 0 & 71 & 170 & 126 & 0 & 164 & 153 & 133 & 49 & 188 & 74 & 134 & 1262 \\
\hline CLIN. MÉD. & 275 & 328 & 336 & 263 & 354 & 399 & 257 & 297 & 305 & 228 & 192 & 383 & 3617 \\
\hline COLOSTOMIA & 2457 & 2656 & 0 & 5387 & 2190 & 3321 & 133 & $401 B$ & 2513 & 2685 & 2338 & 2495 & 30391 \\
\hline ENFERMAGEM & 1446 & 1443 & 2001 & 2202 & 1558 & 1644 & 1863 & 1740 & 1971 & 1601 & 1707 & 1678 & 20854 \\
\hline FISIOTERAPIA & 247 & 353 & 1685 & 391 & 1195 & 1175 & 1489 & 1456 & 1622 & 1394 & 1247 & 484 & 12738 \\
\hline FONOAUDIOL & 452 & 495 & 1122 & 1380 & 1050 & 1233 & 934 & 1268 & 1245 & 1233 & 1171 & 1296 & 12879 \\
\hline FST consolidada & 454 & 415 & 743 & 1983 & 680 & 820 & 1317 & 2582 & 2500 & 2394 & 2229 & 2664 & 18781 \\
\hline GERIATRIA & 21 & 103 & 170 & 216 & 201 & 227 & 213 & 220 & 141 & 192 & 129 & 0 & 1833 \\
\hline NEUROLOGIA & 59 & 242 & 123 & 277 & 165 & 137 & 117 & 176 & 150 & 102 & 196 & 154 & 1898 \\
\hline NUTRIC̄ÃO & 21 & 53 & 168 & 219 & 32 & 230 & 97 & 76 & 151 & 140 & 74 & 130 & 1391 \\
\hline ODONTOLOGIA & 39 & 0 & 130 & 211 & 84 & 69 & 96 & 105 & 80 & 51 & 63 & 47 & 975 \\
\hline ORTOPEDIA & 139 & 114 & 56 & 93 & 191 & 192 & 159 & 175 & 214 & 141 & 116 & 139 & 1729 \\
\hline PEDIATRIA & 247 & 122 & 231 & 302 & 224 & 215 & 223 & 303 & 238 & 180 & 184 & 242 & 2711 \\
\hline PSICOLOGIA & 128 & 123 & 194 & 464 & 369 & 463 & 571 & 499 & 464 & 575 & 562 & 524 & 4826 \\
\hline PSQUIATRIA & 134 & 68 & 133 & 111 & 110 & 120 & 81 & 158 & 117 & 126 & 140 & 58 & 1375 \\
\hline SERV SOCIAL & 410 & 347 & 319 & 571 & 482 & 533 & 382 & 347 & 501 & 477 & 528 & 382 & 5279 \\
\hline TER, OCUPAC. & 254 & 500 & 779 & 878 & 871 & 902 & 879 & 925 & 1136 & 896 & 883 & 872 & 9775 \\
\hline TOTAL: & 6783 & 7433 & 8360 & 15074 & 9756| & 11853 & 8974 & 14466 & 13397| & 12803 & 11833 & 11682 & 132414] \\
\hline
\end{tabular}




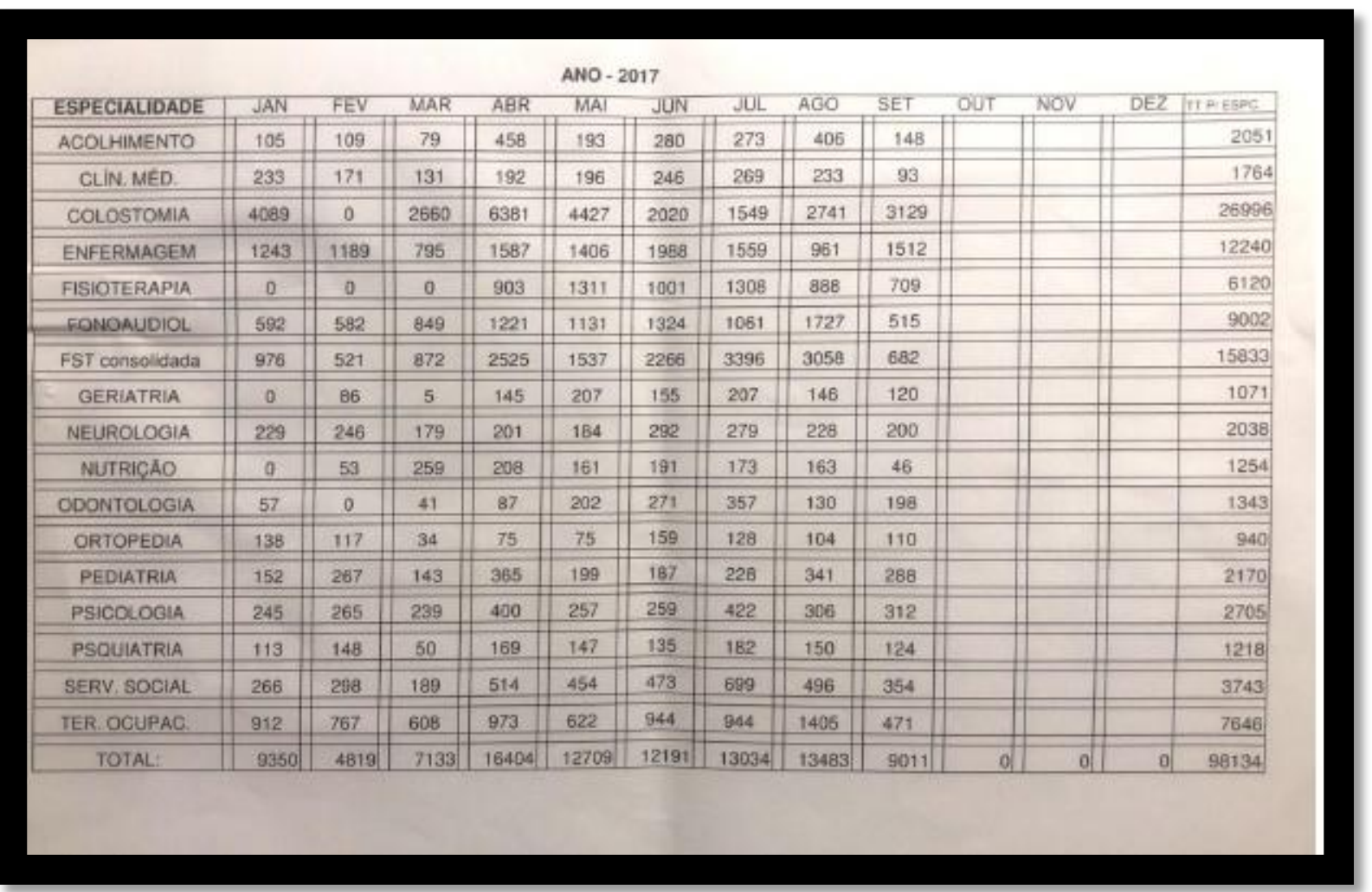

\begin{tabular}{|c|c|c|c|c|c|c|c|c|c|c|c|c|c|}
\hline ESPECIALIDADE & JAN & FEV & MAR & ABR & $\begin{array}{l}\text { ANO - } 2 \\
\text { MAI }\end{array}$ & JUN & JUL & $A G O$ & SET & क्ण & NOV & DEZ & TTAESPC \\
\hline ACOLHIMENTO & 42 & 14 & BB & 62 & 53 & 50 & 65 & 37 & 62 & 24 & 11 & 16 & 524 \\
\hline CLIN MED. & 172 & 25 & 74 & 121 & 150 & 149 & 89 & 127 & 71 & 48 & 58 & 207 & 1291 \\
\hline COLOSTOMIA & 5.043 & 3.076 & 2.944 & 5.253 & 3.585 & 3.210 & 3.139 & 3.012 & 3.770 & 2.840 & 3067 & 1660 & 40599 \\
\hline ENFERMAGEM & 90 & 101 & 136 & 104 & 36 & 103 & 90 & 75 & 56 & 177 & 103 & 43 & 1114 \\
\hline FISIOTERAPIA & 1.375 & 840 & 1.831 & 1.645 & 1.601 & 1767 & 1.581 & 1.200 & 1.845 & 1.552 & 1266 & 680 & 17183 \\
\hline FONDAUDIOL & 567 & 506 & 1.145 & 1.173 & 837 & 960 & 919 & 1.327 & 1.038 & 1.109 & 1029 & 975 & 11585 \\
\hline GERIATRLA & 0 & 88 & 168 & 126 & 164 & 182 & 179 & 103 & 18 & 164 & 198 & 108 & 1498 \\
\hline NEUROLOOGIA & 278 & 118 & 346 & 190 & 252 & 249 & 186 & 271 & 307 & 301 & 112 & 50 & 2660 \\
\hline NUTRICAO & 70 & 79 & 113. & 66 & 50 & 60 & 0 & 22 & 46 & 60 & 44 & 57 & 677 \\
\hline ODONTOLOGIA & 202 & 109 & 253 & 230 & 156 & 429 & 167 & 226 & 185 & 116 & 257 & 334 & 2059 \\
\hline ORTOPEDIA & $20 B$ & 83 & 190 & 135 & 226 & 181 & 82 & 53 & 70 & 135 & 147 & 90 & 1598 \\
\hline PEOIATRIA & 223 & 87 & 240 & 209 & 256 & 273 & 221 & 215 & 206 & 308 & 318 & 207 & 2763 \\
\hline PSICOLOQIA & 75 & 239 & 198 & 147 & 123 & 136 & 110 & 210 & 134 & 231 & 144 & 142 & 1089 \\
\hline PSQUIATRIA & 237 & 158 & 179 & 187 & 88 & 150 & 83 & 116 & 256 & 255 & 208 & 310 & 2227 \\
\hline SERV, SOCIAL & 310 & 123 & 293 & 223 & 197 & 232 & 176 & 152 & 190 & 255 & 291 & 141 & 2523 \\
\hline TER, OCUPAC. & 895 & 631 & 1.273 & 741 & 735 & 523 & 1,142 & 771 & 969 & 728 & 673 & 547 & 9618 \\
\hline TOTAL: & 9775. & 6272 & 9471] & 10612 & 8518 & 8654 & 8229 & 7917 & 9223 & 8303 & 7866 & 5567 & 100408 \\
\hline
\end{tabular}

Figura 1 - Estatísticas do CER II, Duque de Caxias. 
Fonte: Estas estatísticas foram obtidas junto à Diretoria do CER, por entrevista direta à funcionária da Diretoria Ângela Malaquias, em 07/05/2019, e exame da estatística da clínica fornecida pela mesma.

Levando em consideração os dados apresentados pelo próprio Munícipio em seu portal de transparência, em 2018, o total do orçamento destinado à atenção às pessoas com deficiência de foi $\mathrm{R} \$ 45.000,00$. Vê-se que o valor disponibilizado pelo município jamais seria capaz de manter o funcionamento do CER II, que atende, em média, 100.000 (cem mil) pessoas com deficiência por ano e custa de $\mathrm{R} \$ 1,680$ milhão anuais.

Da colheita dos dados, é simples verificar a importância da política pública custeada pela União, que o Munícipio claramente não teria como suportar sozinho. Centenas de milhares de pessoas são beneficiadas com o atendimento, que é possibilitado através das verbas de reforma de imobiliário e equipamento, além da verba de custeio mensal, para manutenção. Ressalte-se que durante a qualificação do CER II, foram oferecidos cursos através da Plataforma do Ministério da Saúde aos profissionais da unidade.

Pais de pacientes costumam externar sua satisfação com o CER. Em reportagem do Jornal O Dia, pode-se extrair essa conclusão:

Os pais da paciente Mariana Esperança de Souza, de 8 anos, Bernardino Oliveira e Ana Maria Elias de Souza, contaram que tinham que ir para outro município realizar o tratamento da portadora de paralisia cerebral.

"Antigamente, nós procurávamos tratamento para Mariana e não conseguíamos, a não ser que a gente se deslocasse para longe. Quando descobrimos o CER IV, ficamos muito felizes porque aqui ela tem todos os tratamentos que teria na Barra e com profissionais maravilhosos. Graças a Deus, nós percebemos melhoras nela e o carinho como ela é recebida", explicou Bernardino. (O DIA. 2019)

Conforme dito alhures, a agenda pública considerada neste trabalho é a necessidade na melhora da saúde, física e mental, e cada vez mais integração em todos os espaços, da pessoa com deficiência. A formulação e escolha da política advém da demanda social por melhorias e maior visibilidade a este segmento da população, o que vem ocorrendo desde a década de 1990. Os atores envolvidos são os agentes do Ministério da Saúde, da secretaria de Saúde do 
ente menor em questão, a própria diretoria do CER, seus agentes de saúde, os pacientes e seus familiares.

Na definição de Jenkins (1978), política pública é o "conjunto de decisões interrelacionadas, tomadas por um ator ou grupo de atores políticos, e que dizem respeito à seleção de objetivos e dos meios necessários para lográ-los, dentro de uma situação específica em que o alvo dessas decisões estaria, em princípio, ao alcance efetivo desses atores". Retomando as fases, ou ciclos, da política pública, mais acima descritos, é possível enquadrar os CERs enquanto política pública, dentro do Plano Nacional de Saúde da Pessoa com Deficiência.

Foi elaborada uma política central, sendo sua execução de responsabilidade dos entes locais, com financiamento e fiscalização feitas pela União. Tudo no intuito de apresentar uma solução ao problema público da ainda não integralização total da pessoa com deficiência e tendo em vistas a melhora da qualidade de vida destas pessoas.

Através da demonstração do financiamento, e de estatísticas do número de atendimentos efetuados nos últimos três anos, é possível deduzir que os CERs funcionam. Que há atendimento efetivo, e que um número significativo da população do município é beneficiado. A parcela da população que consegue acesso aos CERs aproveita diretamente da política.

A crítica que se faz ao projeto do Governo Federal é que ele deveria ser maior: seria extremamente produtivo se mais municípios, e mais Estados, pudessem ofertar à sua parcela deficiente da população o atendimento multidisciplinar que o CER oferece. Apesar de ser uma excelente amostra do que pode ser feito, há ainda muito mais a ser alcançado: acreditamos que as pessoas com deficiência merecem maior espaço na Agenda governamental, merecem maior atenção, uma gama maior de políticas a elas direcionadas. Deixamos aqui a sugestão de ampliação da política, pois, conforme demonstrado no início do trabalho, há um grande quantitativo de pessoas portadoras de deficiência dentro da demografia nacional: quanto mais CERs, mais pessoas seriam potencialmente beneficiadas.

Por fim, ressaltamos que o Ministério da Saúde avaliou tão bem o CER II Duque de Caxias, que em novembro de 2018, foi inaugurado no mesmo Município o CER IV, com as especialidades próprias destes.

\section{CONCLUSÃO}


A inclusão efetiva na vida social e comunitária, a acessibilidade, a não discriminação e a melhora da qualidade de vida são temas inerentes aos direitos humanos e representam aspectos do respeito e da valorização da diversidade humana. Pessoas com deficiência são apenas uma dentre a enorme gama das diferentes roupagens do que significa ser humano. A integração é dever da sociedade e do Estado.

A Política Nacional da Pessoa com Deficiência é um grande salto para o Brasil em termos de desenvolvimento humano. O Plano Nacional de Saúde da Pessoa com Deficiência foi instituído através da Portaria n. ${ }^{\circ} 1.060$, de 5 de junho de 2002 é um ponto de partida que marca a preocupação estatal com a qualidade de vida da pessoa com deficiência. Dez anos mais tarde, a Portaria n. ${ }^{\circ} 835$ de 2012 do Ministério da Saúde trouxe um repasse de verbas federais voluntárias, materializados através de convênios com os entes interessados e que cumprissem os requisitos impostos pelo Ministério da Saúde.

Como aspectos negativos, destaco, unicamente, o tamanho do projeto. Poderia ser deveras maior, mais amplo, e estendido não somente a alguns municípios e Estados, mas, a todos. Isto, tendo em vista o crescimento demográfico da parcela da população que vive com algum tipo de deficiência física ou intelectual. Isso exigiria uma ampliação da agenda da integração das pessoas com deficiência, inclusive, levando em consideração o espírito do Estatuto da Pessoa com Deficiência que tem o condão a independência cada vez maior destas pessoas, em todos os segmentos da vida.

Outro aspecto negativo que restou claro com o empirismo, foi a incapacidade financeira de os municípios se manterem. Apesar do protagonismo jurídico que o ente menor ganhou com a Constituição de 1988, vê-se que, no plano fático, até municípios ricos como Duque de Caxias ainda dependem do repasse dos entes maiores para sustentar grande parte de suas políticas.

A finalidade das verbas repassadas é construir, reformar e manter clínicas multidisciplinares para pessoas com deficiências físicas e mentais. Dentro do Plano Nacional da Pessoa com Deficiência, os Centros Especializados em Reabilitação merecem imenso destaque. A ideia de uma política pública criada pelo maior ente, financiando os projetos dos entes menores que atendem aos interesses da população local é de uma inteligência admirável. Sua consonância com o federalismo de cooperação e com a dignidade da pessoa humana trazem contornos de solidariedade, cumprindo a missão do art. 1. ${ }^{\circ}$ da CRFB. 
Durante a pesquisa, foi possível acompanhar a melhora da qualidade de vida de algumas pessoas, por amostragem. Sendo certo que, se os demais CERs funcionarem como funcionam o CER Duque de Caxias, muito tem a ganhar a população com a implementação de uma política se saúde pública tão eficiente, o que transparece com a apresentação dos dados e a quantidade significativa de pessoas atendidas.

\section{REFERÊNCIAS}

ASSOCIAÇÃO BRASILEIRA DE NORMAS TÉCNICAS (ABNT). NBR 9050: acessibilidade a edificações, mobiliário, espaços e equipamentos urbanos. 2. ed. Rio de Janeiro: ABNT, 2004.

BIRKLAND, Thomas A. An Introdution to the Policy Process: Theories, Concepts and Models of Public Policy Making. 3. ed. Nova Iorque e Londres: M. E. Sharpe, 2011.

BRASIL. Constituição da República Federativa do Brasil de 1988. Disponível em: . Acesso em: 13 mar. 2019.

BRASIL. Decreto n.o 6.949, de 25 de agosto de 2009. Promulga a Convenção Internacional sobre os Direitos das Pessoas com Deficiência. Disponível em: . Acesso em: 19 nov. 2016.

BRASIL. Lei n.o 10.216, de 06 de abril de 2001. Dispõe sobre a proteção e os direitos das pessoas portadoras de transtornos mentais e redireciona o modelo assistencial em saúde mental. Disponível em: . Acesso em: 11/06/2019.

BRASIL. Lei n.o 13.146, de 06 de julho de 2015. Institui a Lei Brasileira de Inclusão da Pessoa com Deficiência (Estatuto da Pessoa com Deficiência). Disponível em: . Acesso em: 19 nov. 2016.

BRASIL. Ministério da Saúde. Portaria SAS/MS n.o 224, de 29 de janeiro de 1992. Disponível em: . Acesso em:11/06/2019.

BRASIL. Portaria n.o 1060, de 5 de junho de 2002. Disponível em: . Acesso em: 11/06/2019/ BRASIL. Ministério da Saúde. Portaria n.o 793, de 24 de abril de 2012. Institui a Rede de Cuidados à Pessoa com Deficiência no âmbito do Sistema Único de Saúde. Disponível em: . Acesso em: 11/06/2019.

BRASIL. Ministério da Saúde. Portaria n.o 835, de 25 de abril de 2012. Institui incentivos financeiros de investimento e de custeio para o Componente Atenção Especializada da Rede de Cuidadosà Pessoa com Deficiência no âmbito do Sistema Único de Saúde. Disponível em: . Acesso em: 11/06/2019. 
BRASIL. Ministério da Saúde. Saúde da pessoa com deficiência: diretrizes, políticas e ações. Disponível em: . Acesso em: 20 abr. 2019.

BRASIL. Ministério da Saúde. Manual de ambiência dos Centros Especializados em Reabilitação. Disponível em: . Acesso em: 05 jun. 2019.

BRASIL. Presidência da República Secretaria Nacional de Promoção dos Direitos da Pessoa com Deficiência. Secretaria de Direitos Humanos da Presidência da República. Avanços das políticas públicas para as pessoas com deficiência: uma análise a partir das conferências nacionais. Brasília, 2012. Disponível em: . Acesso em: 01/04/2019.

BRASIL. Secretaria Especial dos Direitos da Pessoa com Deficiência. Recomendação n.o 01, de 24 de abril de 2014. Dispõe sobre a orientação a ser dada aos gestores estaduais e municipais para criação de órgãos gestores da política da pessoa com deficiência e dá outras providências. Disponível em: . Acesso em: 22 nov. 2016.

CENTRO de Reabilitação em Caxias atende pacientes com deficiência. O Dia, 21 maio 2019. Disponível em: . Acesso em: 08 jun. 2019.

CONSULTÓRIO ORGANIZACIONAL DA MENTE. Entidades que atendem autistas - Rio de Janeiro. Disponível em: . Acesso em: 29 mar. 2019.

FARIAS, Paulo José Leite. Competência federativa e proteção ambiental. Porto Alegre: Sergio Antônio Fabris, 1999.

FONTE, Eliane Maria Monteiro. Da institucionalização da loucura à reforma psiquiátrica: as sete vidas da agenda pública em saúde mental no Brasil. Revista do Programa de pósgraduação em Sociologia da UFPE, v. 1, n. 18, 2012. Disponível em: . Acesso em: 22 maio 2019.

FONTE, Felipe de Melo. Políticas públicas e direitos fundamentais. 2. ed. São Paulo: Saraiva, 2015.

HOWLETT, Michael; RAMESH, M.; PERL, Anthony. Studying Public Policy. Policy Cycles \& Policy Subsystems. Oxford: Oxford University Press, 2009.

INSTITUTO BRASILEIRO DE GEOGRAFIA E ESTATÍSTICA (IBGE). Censo demográfico 2010: banco de dados agregados do IBGE. Disponível em: . Acesso em: 26 abr. 2017.

IOCKEN, Sabrina Nunes. O controle compartilhado das políticas públicas: uma nova racionalidade para o exercício democrático pela sociedade da desconfiança. Tese (Doutorado) - Universidade Federal de Santa Catarina, Florianópolis, 2017.

JENKINS, William. Policy Analysis. A Political and Organizational Perspective. Oxford: Blackwell, 1978. 
LOSCHI, Marília. Pessoas com deficiência: adaptando espaços e atitudes. Agência IBGE Notícias, 20 set. 2017. Disponível em: . Acesso em: 1.o maio 2019.

LOWI, Theodor. American Business, Public Policy, Case Studies and Political Theory. World Politics, v. 16, p. 677-715, 1964.

LYNN, Laurence E. Designing Public Policy: A Casebook on the Role of Policy Analysis. Santa Monica, EUA: Goodyear, 1980.

MOVIMENTO DOWN. Rede de atendimento. Disponível em: . Acesso em: 29 mar. 2019.

NERY JUNIOR, Nelson. Princípios do processo civil na constituição federal. 5. ed. rev. e ampl. São Paulo: Revista dos Tribunais, 1999.

OLIVEIRA, Carolina. Um retrato do autismo no Brasil. Revista Espaço Aberto, São Paulo, v. $170,2018$.

PREFEITURA MUNICIPAL DO RIO DE JANEIRO. Centro de Atenção Psicossocial (CAPS). Disponível em: . Acesso em: 20 maio 2017.

SOUZA, Celina. Políticas públicas: uma revisão da literatura. Sociologias, Porto Alegre, v. 8, n. 16, p. 20-45, jul./dez. 2006.

TRIBUNAL DE CONTAS DO ESTADO DO RIO DE JANEIRO (TCE RJ). Secretaria Geral de Planejamento. Estudos Socioeconômicos. Municípios do Estado do Rio de Janeiro - 2017: Duque de Caxias. Disponível em: . Acesso em: 11/06/2019. 